\title{
IMPLEMENTING KAIZEN BLITZ TO PROMOTE THE ENERGY EFFICIENCY SCHEME IN AN ORGANIZATION
}

\author{
KARIN KANDANANOND \\ Faculty of Industrial Technology, Valaya Alongkorn Rajabhat University, Thailand
}

\section{ABSTRACT}

Energy efficiency is an important issue for every organization. The implementation of the appropriate improvement technique will lead to the reduction of the energy consumption. The objectives of this study include the creation of the following improvement tool kits: a drafted Kaizen event program, an example of cause-and-effect diagram, an example of Kaizen newspaper, and a drafted questionnaire, so they will be subsequently introduced to the organization executives. At first, a Kaizen event program was elaborately drafted, and the total period of the program lasted for six days. The drafted program briefly included the kick-off date, Kaizen-concept review, technical training, the analysis and design of current and future states of energy consumption, the improvement action, the establishment of best practice to reduce the energy consumption, the documentation of standard work, and the presentation. An example of cause-and-effect diagram was also developed, and the different areas of sample root cause analysis were based on measurement, method, machine, manpower, and environment. Later, an example of Kaizen newspaper was prepared, and it consisted of the sample analysis in these categories: the root causes of problems, actions, responsible persons, place, and the phase of improvement. Finally, a questionnaire was drafted and intended to be utilized for an assessment of the sustainability of the energy efficiency program.

KEYWORDS: Cause-and-effect diagram, energy consumption, Kaizen blitz, Kaizen newspaper, organization, questionnaire

Received: Jan 21, 2021; Accepted: Feb 10, 2021; Published: Feb 11, 2021; Paper Id.: IJMPERDAPR20212

\section{INTRODUCTION}

Kaizen is a practice to initiate the continuous improvement in the organization. The concept of Kaizen is the improvement which requires the cooperation of task force in the workplace. The implementation of Kaizen is not only limited to product quality but also many aspects of work. Kaizen blitz is another practice developed from the concept of Kaizen. Instead of focusing on an improvement over time, the practice of Kaizen blitz aims to carry out the rapid improvement over a limited time. As a result, the important highlight of Kaizen blitz is the quick removal of waste in the process. The improvement is possible by analyzing the current state and designing the future state, identifying root causes and problems, implementing the appropriate actions, and establishing the new standard work. At present, the energy efficiency is a critical issue which needs a continuous and sustainable attention in every organization. The implementation of the appropriate method in an organization will lead to the significant reduction in energy consumption. Therefore, the results of this research (a drafted Kaizen event program, an example of cause-and-effect diagram, an example of Kaizen newspapers, and a drafted questionnaire) will be subsequently proposed to executives.

\section{LITERATURE REVIEW}

The benefits of applying Kaizen in the organization was explained by Manos (2007) and these includes the qualitative 
(motive and positive attitudes) and quantitative (saved money, time, people) benefits. There were studies which show the successful implementation of Kaizen blitz in many organizations, ranged from manufacturing, healthcare, service to public sector. Bane (2002) reported that Kaizen was successfully applied in many industries, e.g., service, education, and nonmanufacturing. According to Lanyon (2003), Kaizen blitz was also proved to be effective when it was implemented to improve the process of human resource management. Radnor and Walley (2008) pointed out the lessons learned from the effective application of Kaizen in public organizations. A study by Norazlan et al (2014) pointed out that Kaizen blitz had the positive impact on the sustainable performance in the healthcare industry. However, there are many studies which signify the limitation and impact of Kaizen blitz. Farris et al (2008) studied the characteristic of businesses which were not successful when Kaizen blitz was implemented. The study indicated that the goal clarity of the event played an important role on the successful implementation of the event. Engelund et al (2009) applied the method of Kaizen blitz to optimize in the production of the large-scale meals in the kitchen. The results showed that the implementation led to the significant increase in the production efficiency as well as the systematic improvement of product quality. Moreover, another advantage was that there was no negative impact on the working environment. The success factors for the implementation were addressed by Kumar and Harms (2004) and they were the standardized work instructions, work measurement tools, and the education of the workforce. The empirical study on the effective implementation of Kaizen event was also studied by Marin-Garcia et al (2009). The intervention after the Kaizen events was observed in the targeted eleven industries and the results showed the limited achievement of the implementation. The soft skills were identified as the key success factors for the implementation of Kaizen events as signified by Garcia et al (2014). These soft skills included management, commitment, education, communication, and motivation. For the energy conservation, different methods were utilized to achieve the goal. Kandananond (2017) applied the method of ecological footprint to calculate the amount of greenhouse gas emission caused by the electrical consumption in an organization. Halldorsson et al (2018) conducted a qualitative study to explore the effectiveness of implementing lean method and the characteristics led to the organizational sustainability in term of energy efficiency improvement. Similarly, the water footprint was utilized by Kandananond (2019) to assess the amount of energy use due to transportation-related fuel and power consumption. The effectiveness of Kaizen event was studied by Gomes et al (2013). The focus of the study was the sustainable layout planning and Kaizen event was used as an important tool for the implementation. Venkatesan \& Kundu (2020) analyzed the practice of Kaizen event in Indian small and medium enterprises. The objective was the reduction of energy use as well as Carbon emissions.

\section{METHODS}

Energy is a resource which is highly consumed in the organization. Therefore, the significant improvement in a short period of time is desired and the involvement of people in the organization is a critical key of success. Moreover, the sustainability is another important factor to be concerned in this study. To begin with the study, a Kaizen event program for the period of six days was drafted and the Kaizen agenda is shown in Table 1-5. The drafted agenda in the kick-off day (day 1) is depicted in Table 1 while Table 2 illustrates the drafted agenda in day 2 . The drafted agenda on day 3 is elaborated in Table 3 and the drafted agenda of day 4-5 is shown in Table 4. Eventually, Table 5 lists the drafted agenda of the last day. According to Table 1, the first-day agenda is the event kick-off which includes the review section regarding the different aspects of Kaizen method. The second-day agenda (Table 2) covers the technical topics of energy efficiency and these are air conditioning system, lighting system, pumping system, solar energy, the measurement of energy consumption, and the assessment of greenhouse gas emission. The third-day agenda (Table 3) includes the analysis of current state and the design of future state of the energy consumption. The root cause analysis will be performed by developing a cause-and-effect diagram. The next 
two days (day 4-5) activities are observation, the implementation of change, data collection, and the establishment of the best practice and new standard work (Table 5). These activities should be performed with the smallest impact on the current operation. The drafted daily activities are divided into two sections. The morning section is the activity of team meeting and the rest of the day is focusing on the improvement action. One of the effective tools is the utilization of Kaizen newspaper which is the list of actions to be implemented. There is a debrief section on every evening. On the last day (day 6), the morning activity is the report on the finalization of improvement (Table 5). The best practice and standard work will be reported, and the presentation will be carried out.

Table 1: Drafted Kaizen agenda (first day)

\begin{tabular}{|l|l|l|l|}
\hline \multicolumn{1}{|c|}{ Day 1 } & \multicolumn{1}{c|}{ Time } & \multicolumn{1}{c|}{ Place } & Person \\
\hline Kick-off for orientation and introduction & $8: 30-9: 30$ & & \\
\hline Department (or building) tour & $9: 30-12: 00$ & & \\
\hline Lunch & $12: 00-13: 00$ & & \\
\hline Kaizen method Review & $13: 30-14: 15$ & & \\
\hline Break & $14.15-14: 30$ & & \\
\hline Kaizen method review (continue) & $14.45-16: 00$ & & \\
\hline Team selection + Conclusions & $16: 00-16: 30$ & & \\
\hline
\end{tabular}

Table 2: Drafted Kaizen agenda (day 2)

\begin{tabular}{|l|l|l|l|}
\hline \multicolumn{1}{|c|}{ Day 2 (Energy efficiency training) } & \multicolumn{1}{c|}{ Time } & Place & Person \\
\hline Air conditioning and lighting system & $8: 30-10: 00$ & & \\
\hline Break & $10: 00-10: 15$ & & \\
\hline Pumping system and solar energy & $10: 15-12: 00$ & & \\
\hline Lunch & $12: 00-13: 00$ & & \\
\hline Measurement of energy consumption & $13: 00-14: 15$ & & \\
\hline Break & $14.15-14: 30$ & & \\
\hline Greenhouse gas assessment & $14: 30-16: 30$ & & \\
\hline
\end{tabular}

Table 3: Drafted Kaizen agenda (day 3)

\begin{tabular}{|l|l|l|l|}
\hline \multicolumn{1}{|c|}{ Day 3 } & \multicolumn{1}{|c|}{ Time } & Place & Person \\
\hline Daily morning meeting & $8: 30-9.30$ & & \\
\hline $\begin{array}{l}\text {-Analyze a current state of energy consumption } \\
\text {-Develop a cause-and-effect diagram }\end{array}$ & $9: 30-12: 00$ & & \\
\hline Lunch & $12: 00-13: 00$ & & \\
\hline Design a future state of energy consumption & $13: 00-15.30$ & & \\
\hline Break fute of energy consumption & $15.45-16.30$ & & \\
\hline $\begin{array}{l}\text { Design a future state } \\
\text { (continue) }\end{array}$ & & & \\
\hline
\end{tabular}


Table 4: Drafted Kaizen agenda (day 4-5)

\begin{tabular}{|l|l|l|l|}
\hline \multicolumn{1}{|c|}{ Day 4-5 } & \multicolumn{1}{c|}{ Time } & \multicolumn{1}{c|}{ Place } & Person \\
\hline Daily morning meeting & $8: 30-9.30$ & & \\
\hline Improvement action & $9: 30-12: 00$ & & \\
\hline Lunch & $12: 00-13: 00$ & & \\
\hline Improvement action & $13: 00-15.30$ & & \\
\hline Break & $15.30-15.45$ & & \\
\hline Daily reports + Debrief & $15.45-16.30$ & & \\
\hline
\end{tabular}

Table 5: Drafted Kaizen agenda (day 6)

\begin{tabular}{|l|l|l|l|}
\hline \multicolumn{1}{|c|}{ Day 6 } & Time & Place & Person \\
\hline Daily morning meeting & $8: 30-9.30$ & & \\
\hline $\begin{array}{l}\text {-The finalization of improvement } \\
\text {-Debrief on standard work and the best practice of the reduction } \\
\text { of energy consumption }\end{array}$ & $9: 30-12.00$ & & \\
\hline Lunch & $12: 00-13: 00$ & & \\
\hline Presentation & $13: 00-15: 00$ & & \\
\hline
\end{tabular}

\section{RESULTS}

Two examples of cause-and-effect diagram and Kaizen newspaper were presented in this section. The focused process is the energy consumption in a building. An example of cause-and-effect diagram was created and shown in Figure 1. According to Figure 1, the result from the cause-and-effect diagram indicates that there are many categories of causes (measurement, method, machine, manpower, and environment). In each category, there are branches of causes, e.g., under "measurement", there are the example of causes: measuring equipment availability, equipment calibration, and data logger availability.

\section{Measurement}

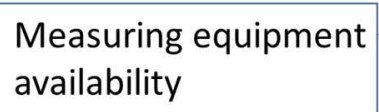

\section{Method}

$$
\begin{aligned}
& \text { Data logger } \\
& \text { availability }
\end{aligned}
$$

Work from home

Efficient use of energy

\section{Elevator use}

Lighting

A/C use Old electrical appliance and light fixture replacement

\section{Discipline \& awareness}

Environment
Manpower

\section{Machine}

Figure 1: Example of cause-and-effect diagram. 
Table 6: Example of Kaizen newspaper

\begin{tabular}{|l|l|l|l|l|}
\hline \multicolumn{1}{|c|}{ Root cause and problem } & \multicolumn{1}{|c|}{ Action } & \multicolumn{1}{|c|}{ Person } & $\begin{array}{c}\text { Phase of } \\
\text { improvement } \\
\text { (p/d/c/a) }\end{array}$ \\
\hline $\begin{array}{l}\text { High electricity bill due to } \\
\text { elevator use }\end{array}$ & $\begin{array}{l}\text {-Promote a campaign to reduce the } \\
\text { use of elevators/ -Use the stair for } \\
\text { one or two floors traveling } \\
\text {-Physical plant } \\
\text { dept. A building } \\
\text {-Staffs in the } \\
\text { building } \\
\text { air conditioners use }\end{array}$ & $\begin{array}{l}\text {-Promote a campaign to turn off air- } \\
\text { conditioners when they are not in } \\
\text { use }\end{array}$ & $\begin{array}{l}\text {-Physical plant } \\
\text { dept. A building } \\
\text {-Staffs in the } \\
\text { building }\end{array}$ & \\
\hline
\end{tabular}

Kaizen newspaper will address the root cause and problem as well as the action measure. The name of responsible person ("who") as well as place ("where") will be assigned as well. The status of improvement will be clearly identified, and the status will be categorized into $\mathrm{P}=$ Plan, $\mathrm{D}=\mathrm{Do}, \mathrm{C}=\mathrm{Check}$, and $\mathrm{A}=$ Act. The example of Kaizen newspaper is listed in Table 6. The sustainability after Kaizen blitz implementation is another critical agenda. Therefore, another step to ensure the sustainability is the utilization of questionnaire which will be distributed to the executives and employees in the organization after the implementation. The goal is to check whether people in the organization is committed to the sustainability through the implementation of Kaizen blitz. The drafted questionnaire after each improvement is shown in Table 7. The scale of the score might follow the Likert's scale, five-point scale, i.e., $5=$ strongly agree, $4=$ agree, $3=$ neutral, $2=$ disagree, $1=$ strongly disagree.

Table 7: Drafted Questionnaire

\begin{tabular}{|l|l|}
\hline \multicolumn{1}{|c|}{ Questions } & Score \\
\hline $\begin{array}{l}\text { The implementation of Kaizen blitz supports the drive for sustainability of energy } \\
\text { efficiency. }\end{array}$ & \\
\hline $\begin{array}{l}\text { The awareness regarding energy efficiency has been embedded as the culture in the } \\
\text { organization. }\end{array}$ & \\
\hline $\begin{array}{l}\text { Most employees understand and support Kaizen blitz activities leading to the energy } \\
\text { efficiency. }\end{array}$ & \\
\hline $\begin{array}{l}\text { Organization executives support the implementation of Kaizen blitz for the } \\
\text { sustainability of energy efficiency. }\end{array}$ & \\
\hline
\end{tabular}

\section{CONCLUSIONS AND DISCUSSIONS}

In this study, a set of improvement tool kits were created. A six-days program of Kaizen event was drafted, and this program includes the review of Kaizen concept, energy efficiency training, the assessment of current state of energy consumption, the design of future state of energy consumption, the identification of root causes, the implementation action, and the establishment of best practice for energy efficiency. An example of cause-and-effect diagram was also drafted as a guideline of how to identify the sample root causes leading to the excessive consumption of energy. Moreover, a drafted Kaizen newspaper was created to identify specific actions matching with the root causes and problems. Finally, a drafted questionnaire was designed, and the objective is to assess the sustainability of the energy efficiency program thereafter. The future study will focus on the introduction of implementation proposal to the executives, getting the approval to hold Kaizen event in the organization, and the performance assessment through the utilization of questionnaire. 


\section{REFERENCES}

1. Bane, R. (2002). Leading edge quality approaches in non-manufacturing organizations, Annual Quality Congress Proceedings, 245-250.

2. Engelund, E.H., Breum, G., \& Friis, A. (2009). Optimisation of large-scale food production using lean manufacturing principles. Journal of Food Service, 20(1), 4-14.

3. Farris, J.A., Van Aken, E.M., Doolen, T.L., \& Worley, J. (2008). Learning from less successful Kaizen events: A case study. Engineering Management Journal, 20(3), 10-20.

4. García, J.L., Maldonado, A.A., Alvarado, A., \& Riviera, D.G. (2014). Human critical success factors for Kaizen and its impacts in industrial performance. International Journal of Advanced Manufacturing Technology, 70, 2187-2198.

5. Gomes, V.E.O., Gomes, J.O., \& Grote, K.-H. (2013). Discrete Event Simulation Inserted into Kaizen Event to Assess Energy Efficiency, Re-engineering Manufacturing for Sustainability, 499-503.

6. Halldorsson, A., Gremyr, I., Winter, A., \& Taghahvi, N. (2018). Lean Energy: Turning sustainable development into organizational renewal. Sustainability, 10(12), 4464-

7. Kandananond, K. (2017). The Greenhouse Gas Accounting of A Public Organization: The Case of A Public University in Thailand. Energy Procedia, 141, 672-676.

8. Kandananond, K. (2019). The Energy Related Water Footprint Accounting of A Public Organization: The Case of A Public University in Thailand. Energy Procedia, 156, 149-153.

9. Kumar, S. \& Harms, R. (2004). Improving business processes for increased operational efficiency: A case study. Journal of Manufacturing Technology Management, 15(7), 662-674.

10. Lanyon, S. (2003). At Raytheon Six Sigma works, too, to improve HR management processes. Journal of Organizational Excellence, 22(4), 29-42.

11. Manos, A. (2007). The benefits of Kaizen and Kaizen events. Quality Progress, 40(2), 47-48.

12. Marin-Garcia, J., Garcia-Sabater, J., \& Bonavia, T. (2009). The impact of Kaizen events on improving the performance of automotive components' first-tier suppliers. International Journal of Automotive Technology and Management, 9(4), 362-376.

13. Norazlan, A.N.I., Habidin, N.F., Rosland, M.H., \& Zainudin, M.Z. (2014). Investigation of Kaizen blitz and sustainable performance for Malaysian healthcare industry. International Journal of Quality and Innovation, 2(3-4).

14. Radnor, Z. \& Walley, P. (2008). Learning to walk before we try to run: Adapting lean for the public sector. Public Money \& Management, 28(1), 13-20.

15. Venkatesan, T.M.I. \& Kundu, G.K. (2020). An empirical study on Kaizen events in Indian small and medium enterprises. International Journal of Services and Operations Management, 37(2). 